\title{
Characterization and Antimicrobial Susceptibility Profiles of Bacteria Isolated from Various Specimens among Mary Begg Health Facilities
}

\author{
Stephen Mwisiya Mubita ${ }^{1}$, Wila Simbile², Barbara Mulunda ${ }^{3}$, Pascal S. Siloozi ${ }^{4}$, \\ Vernon Julius ${ }^{5}$, Mwape Kunda ${ }^{6}$, Jaianth H. Ramnath ${ }^{7}$, Misheck Chileshe ${ }^{8}$ \\ ${ }^{1,2}$ Biomedical Scientist, Mary Begg Health Services, 56 Chintu Avenue, Northrise, P.O. Box 72221, Ndola, \\ Zambia. \\ ${ }^{3}$ Biomedical Technologist, Mary Begg Health Services, Kansanshi Mine Hospital, P.O Box 110385, Solwezi, \\ Zambia. \\ ${ }^{4}$ Biomedical Technologist, Mary Begg Health Services, Trident Town Clinic, P.O Box 72221, Kalumbila, \\ Zambia. \\ ${ }^{5}$ Medical Doctor, ${ }^{6}$ Pharmacist, Mary Begg Health Services, 56 Chintu Avenue, Northrise, P.O. Box 72221, \\ Ndola, Zambia. \\ ${ }^{7}$ Medical Doctor, Mary Begg Health Services, Trident Town Clinic, T5 Mwinilunga Rd, P.O. Box 72221, \\ Kalumbila, Zambia. \\ ${ }^{8}$ Biomedical Scientist, Mary Begg Health Services, Kansanshi Mine Hospital, P.O Box 110385, Solwezi, \\ Zambia.
}

Corresponding Author: Misheck Chileshe

\begin{abstract}
Background: The ever-increasing magnitude of antimicrobial resistance encountered in human pathogens has led to limited treatment options for bacterial infections, consequently reducing antimicrobial efficacy while increasing treatment costs, morbidity, and mortality. In clinical setup, laboratory-based in vitro antimicrobial susceptibility testing is the cornerstone for guiding therapy and enables the monitoring of antimicrobial resistance trends.

Aim: To characterize the distribution of bacteria isolated from various specimens and their antibiotic susceptibility profiles in Mary Begg Health facilities.

Material \& Methods: This was a retrospective, cross-sectional, quantitative, descriptive study that involved the review of 569 laboratory files from three Mary Begg Health facilities from the period of January 2019 to June 2020. A systematic random sampling method was used and SPSS version 21.0 was used for data analysis.

Results: The distribution of bacteria based on Gram stain reaction found that most bacteria that were isolated were Gram negative bacilli, 79.5\% (171/215). The most common bacterium isolated was Escherichia coli, 46.5\% (100/215) followed by Staphylococcus aureus, 12.1\% (26/215) and Klebsiella pneumoniae, $177.9 \%$ (17/215). The study found that E. coli was highly resistant to amoxicillin (95.0\%), Ampicillin (90.0\%) and Cotrimoxazole (77.0\%), respectively. In contrast, E. coli was highly sensitive to Amikacin (96.0\%), Ertapenem (91.0\%) and Ceftriaxone (80.0\%) S. aureus species isolated were sensitive to Gentamicin $(65.4 \%)$ and Clindamycin $(46.2 \%)$ but highly resistant to Cotrimoxazole (80.8\%).

Conclusion: The most frequent isolates were Escherichia coli followed by Staphylococcus aureus and majority of them were from urine specimens.
\end{abstract}

Key words: Antimicrobial, Resistant, Antimicrobial Resistance, Antimicrobial susceptibility testing, Mary Begg Health services. 


\section{INTRODUCTION}

Antibiotics, and more broadly, antimicrobials, have served as a cornerstone of modern medicine for decades, their use being to treat a range of diseases and to support numerous modern medical procedures from organ transplants to chemotherapy. ${ }^{[1,2]}$

Antibiotics are chemical agents that help stop infections caused by bacteria by either killing the bacteria or by inhibiting their growth. The terms antibiotic and antimicrobial are often used interchangeably but do not have the same meaning. Antibiotics are substances of microbial origin (such as penicillin) whilst "antimicrobial" refers to any substance including synthetic compounds that destroys microbes. Antibiotics are used to treat and or prevent disease in humans and animals. ${ }^{[3]}$

The constant increase of antimicrobial resistance (AMR) encountered in human pathogens is a huge concern for public health globally. AMR limits treatment options for bacterial infections and thereby reducing clinical efficacy while increasing treatment costs, morbidity and mortality. ${ }^{[4]}$ With a lack of development of new antibiotics, and increasing resistance even to last-resort antibiotics, there is a need to conserve the ones available. ${ }^{[4,5]}$

There are two ways of categorising antimicrobial resistance (AMR); the first one being intrinsic or natural whereby microorganisms naturally do not possess target sites for the drugs and therefore the drug does not affect them or have a lower permeability because of the discrepancies in the chemical nature of the drug and the microbial membrane structures. [6] The second one is acquired resistance whereby a naturally susceptible microorganism acquires ways of not being affected by the drug. ${ }^{[3]}$

Antibiotic resistance is associated with misuse of antibiotics as a result of several factors including inappropriate prescribing by clinicians and misuse of antibiotics by patients. ${ }^{[7]}$ Inappropriate prescription of antibiotics is found to be positively correlated with inappropriate use of antibiotics. ${ }^{[8]}$ Interventions to curtail the increasing burden of antibiotic resistance $(\mathrm{ABR})$ are therefore urgently needed. Many intervention programs including education for prescribers and consumers (population) have been recommended to help elicit the judicious and appropriate use of antibiotics. [5]

Problems associated with bacterial resistance include; increased morbidity and mortality, longer duration of patient hospitalization, increased cost of health care, the spread of multidrug resistant bacteria and highly resistant bacteria such as Methicillin-Resistant Staphylococcus aureus (MRSA) or multidrug-resistant Gramnegative bacteria. ${ }^{[9]}$

The availability of routine antimicrobial susceptibility testing to provide information on resistance trends, including emerging resistance is very essential for routine clinical practice and for the development of effective policies against AMR. ${ }^{[10]}$ One of the most important methods to confirm bacteria susceptibility to the readily available antibiotics is through laboratory antibiotic susceptibility testing against the isolated bacteria prior to prescribing or use of antibiotics. [11] Laboratory-based in vitro antimicrobial susceptibility testing is the foundation for guiding anti-infective therapy and monitoring antimicrobial resistance trends. [11]

Establishing the trends or patterns of antibiotic susceptibility profiles of the most commonly isolated bacteria in health institutions forms the backbone of institutional policy development suitable for the treatment and management of bacterial infections. Therefore, this study aimed at identifying the most commonly isolated bacteria and their susceptibility profiles within Mary Begg Health Services (MBHS) facilities. These findings would facilitate policy development regarding the treatment of bacterial infections within MBHS and may add value to national antimicrobial 
selection for reference purposes (AMR patterns are area specific).

\section{MATERIALS AND METHODS Study Design}

This was a retrospective, crosssectional, quantitative, descriptive study that involved the review of laboratory files.

\section{Study sites}

Three of Mary Begg Health Service facilities were included in the study, that is, Mary Begg Medical Complex (Ndola), Kansanshi Mine Hospital (Solwezi) and Trident Town Clinic (Kalumbila). The facilities were included on the grounds that no study of this nature has been done within Mary Begg Health Services.

\section{Study Period}

This study was conducted from January 2019 to June 2020

\section{Study Frame/Population}

All the laboratory forms and results of patients for microscopy, culture and sensitivity (MCS) made up the study frame.

\section{Sample size}

Sample size was calculated using the Cochran's formula

$\mathrm{n}=\frac{Z^{2} \times P(1-P)}{d^{2}}$

where: $\mathrm{n}=$ Sample size

$\mathrm{Z}=1.96$ at $95 \%$ confidence interval

$\mathrm{P}=$ Estimated prevalence $(50.0 \%$ since the prevalence of AMR within the country is not known)

$\mathrm{d}=$ Margin of error $(5 \%)$

$\mathrm{n}=\frac{Z^{2} \times P(1-P)}{d^{2}}$

$\mathrm{n}=\frac{(1.96)^{2} \times 0.5(1-0.5)}{(\mathbf{0 . 0 5})^{2}}$

$\mathrm{n}=384.16$

$\mathrm{n}=384$

However, to reduce on error and increase accuracy of the findings, 569 laboratory files and results for MCS were selected and included in this study.

\section{Sampling}

Systematic random sampling method was used to select the files that were reviewed for this study. Every 4th file meeting the inclusion criteria was selected and included in the study. Files from January, 2019 to June, 2020 were retrieved and reviewed. The following inclusion and exclusion criteria were applied

\section{Inclusion Criteria}

All laboratory request forms or files for MCS that had complete clinical details of the patient.

All laboratory result forms for MCS with clear information including Gram stain reaction of the organism, name of bacteria, and antibiotic susceptibility profile.

\section{Exclusion Criteria}

All laboratory request forms and results for MCS with incomplete clinical details and other patient information.

\section{Variables}

Dependent Variables

Antibiotic susceptibility profile

\section{Independent Variables}

Isolated bacteria

Age

Gender

Site of infection or isolation

Nature of sample

\section{Data Analysis}

The data collected was entered into Microsoft excel and cleaned. It was coded and entered into SPSS version 21.0. Descriptive statistics were performed on the demographic characteristics and these results were presented in form of frequency and percentage in tables. A chi-square test of association was performed to assess the association between bacteria distribution with demographic factors and Fisher's exact test for variables with counts less than 5 . Logistic regression was performed to determine factors that could independently predict isolation of bacterial species from a particular specimen. A p-value of less than 0.05 was considered to be statistically significant at $95 \%$ confidence interval. 


\section{Ethics Consideration}

This was a retrospective laboratory based cross-sectional study that did not involve direct contact with patients. However, confidentiality and anonymity were maintained by ensuring that no names or physical addresses of patients were included in the research report. The data that was retrieved from laboratory files were kept on a password protected computer to ensure that the data were not reviewed by an unauthorized person. Permission to use the Mary Begg Health facilities in this research was sought from the Medical director of Mary Begg Health Services. Ethical clearance for this study was obtained from the University of Zambia Health Sciences Research Ethics Committee (UNZAHSREC), Protocol ID: 20203101082.

\section{RESULTS}

\section{Demographics of the participants}

This study reviewed 569 laboratory results files for the patients whose specimens were submitted for microscopy, culture and sensitivity. Majority of the patients whose files were reviewed were aged between 31-45 years, 232 (40.8\%) and most of these patients were males, 293 $(51.5 \%)$. Most of the files that were reviewed were from Trident town clinic (TTC) in Kalumbila and the least were from Kanshashi mine hospital (KMH) in Solwezi, $233(40.9 \%)$ and $149(26.2 \%)$ respectively while 187 (32.9\%) were from Mary Begg Medical Complex in Ndola as shown in table 1.

Table 1: Demographic characteristics of patients whose specimens were used

\begin{tabular}{|l|l|l|l|}
\hline Factor & Frequency & Percent \\
\hline \multirow{5}{*}{ Age } & 0-15 Years & 111 & 19.5 \\
\cline { 2 - 4 } & 16-30 Years & 181 & 31.8 \\
\cline { 2 - 4 } & 31-45 Years & 232 & 40.8 \\
\cline { 2 - 4 } & $>$ 45 Years & 45 & 7.9 \\
\cline { 2 - 4 } & Total & 569 & 100.0 \\
\hline \multirow{5}{*}{ Sex } & Male & 293 & 51.5 \\
& Female & 276 & 48.5 \\
& Total & 569 & 100.0 \\
\hline \multirow{5}{*}{ Location } & TTC & 233 & 40.9 \\
& KMH & 149 & 26.2 \\
& Ndola & 187 & 32.9 \\
& Total & 569 & 100.0 \\
\hline
\end{tabular}

\section{Characteristics of specimens and their site of collection}

The most common specimens that were submitted for MCS out of 569 specimens, were urine 222 (39.0\%), stool (faeces) 65 (11.4\%), pus swabs 55 (9.7\%), blood $53(9.3 \%)$ and high vaginal swabs 51 $(9.0 \%)$ as shown in table 2. Majority of the specimen were collected from the urinary tract system, $43.6 \%$ and the least from the eye, $0.2 \%$.

Table 2: Characteristics of Specimen and site of collection

\begin{tabular}{|c|c|c|c|}
\hline Variable & . & Frequency & Percent \\
\hline Specimen type & Urine & 222 & 39.0 \\
\hline & HVS & 51 & 9.0 \\
\hline & Pus Swab & 55 & 9.7 \\
\hline & Throat Swab & 14 & 2.5 \\
\hline & Ear Swab & 12 & 2.1 \\
\hline & Blood & 53 & 9.3 \\
\hline & Urethral Swab & 25 & 4.4 \\
\hline & Stool (faeces)s & 65 & 11.4 \\
\hline & Sputum & 19 & 3.3 \\
\hline & Wound Swab & 35 & 6.2 \\
\hline & Semen & 2 & .4 \\
\hline & Eye Swab & 1 & .2 \\
\hline & Pleural fluid & 12 & 2.1 \\
\hline & CSF & 3 & .5 \\
\hline & Total & 569 & 100.0 \\
\hline Site of Collection & & & \\
\hline & $\begin{array}{l}\text { Urinary Tract } \\
\text { Vagina }\end{array}$ & $\begin{array}{l}248 \\
51\end{array}$ & $\begin{array}{l}43.6 \\
9.0\end{array}$ \\
\hline & Throat & 14 & 2.5 \\
\hline & Dermal & 68 & 12.0 \\
\hline & Ear & 33 & 5.8 \\
\hline & Palate & 1 & .2 \\
\hline & Respiratory Tract & 19 & 3.3 \\
\hline & GUT & 2 & .4 \\
\hline & Vein & 53 & 9.3 \\
\hline & GIT & 65 & 11.4 \\
\hline & Eye & 1 & .2 \\
\hline & Pleural cavity & 11 & 1.9 \\
\hline & CNS & 3 & \\
\hline & Total & 569 & 100.0 \\
\hline
\end{tabular}

Growth of organisms among the specimens

Table 3: Distribution of organisms isolated

\begin{tabular}{|l|l|l|l|}
\hline Growth characteristics & Frequency & Percent \\
\hline \multirow{2}{*}{$\begin{array}{l}\text { Growth organism } \\
\text { of }\end{array}$} & Yes & 247 & 43.4 \\
\cline { 2 - 4 } & No & 322 & 56.6 \\
\cline { 2 - 4 } & Total & 569 & 100.0 \\
\hline Organism isolated & Bacteria \& & 200 & 35.1 \\
& Bacteria & 15 & 2.6 \\
& Fungi & 32 & 5.6 \\
& Fungi & 322 & 56.6 \\
& No growth & 569 & 100.0 \\
& Total & & \\
\hline Candida albicans & Present & 47 & 8.3 \\
& Absent & 522 & 91.7 \\
& Total & 569 & 100.0 \\
\hline
\end{tabular}

Of the 569 specimens, $247(43.4 \%)$ had growth of organisms and of these 
Stephen M. Mubita et.al. Characterization and antimicrobial susceptibility profiles of bacteria isolated from various specimens among mary begg health facilities.

growths, 215 (37.8\%) were identified to be bacterial growths. Candida albicans was isolated in $47(8.3 \%)$ of the total specimens that were cultured as shown in table 3 .

\section{Classification of isolated bacteria}

Within the specimens with bacterial growth $87.1 \%$ (215/247), the distribution based on Gram stain reaction found that most bacteria that were isolated were Gram negative bacilli, 215 (79.5\%). The most common bacterium isolated was Escherichia coli, $100(46.5 \%)$ which was far in frequency from Staphylococcus aureus, 26 (12.1\%) and Klebsiella pneumoniae, 17 (17 $7.9 \%$ ) as indicated in table 4.

Table 4: Distribution of bacterial species isolated

\begin{tabular}{|c|c|c|c|}
\hline \multicolumn{2}{|l|}{ Bacterial properties } & Frequency & Percent \\
\hline \multirow[t]{3}{*}{ Gram stain reaction } & Gram Negative Bacilli & 171 & 79.5 \\
\hline & Gram Positive Cocci & 44 & 20.5 \\
\hline & Total & 215 & 100.0 \\
\hline \multirow[t]{24}{*}{ Bacterial species } & Escheriachia coli & 100 & 46.5 \\
\hline & Pseudomonas aeruginosa & 8 & 3.7 \\
\hline & Klebsiella pneumoniae & 17 & 7.9 \\
\hline & Klebsiella oxytoca & 6 & 2.8 \\
\hline & Proteus mirabilis & 10 & 4.7 \\
\hline & Raoultella ornithinolytica & 3 & 1.4 \\
\hline & Enterobacter cloacae & 1 & .5 \\
\hline & Enterobacter aerogenes & 1 & .5 \\
\hline & Pseudomonas flourescens & 2 & .9 \\
\hline & Serratia odorifera & 1 & .5 \\
\hline & Aeromonas hydrophila & 2 & .9 \\
\hline & Serratia species & 3 & 1.4 \\
\hline & Pseudomonas species & 11 & 5.1 \\
\hline & Staphylococcus aureus & 26 & 12.1 \\
\hline & Streptococcus agalactiae & 3 & 1.4 \\
\hline & Staphylococcus saprophyticus & 2 & .9 \\
\hline & Streptococcus pyogenes & 1 & .5 \\
\hline & Enterococcus faecalis & 11 & 5.1 \\
\hline & Enterococcus faecium & 1 & .5 \\
\hline & $M R S A$ & 1 & .5 \\
\hline & Proteus vulgaris & 3 & 1.4 \\
\hline & Acinetobacter iwoffii & 1 & .5 \\
\hline & Acinetobacter baumannii & 1 & .5 \\
\hline & Total & 215 & 100.0 \\
\hline
\end{tabular}

\section{Bacterial distribution by specimen types}

Table 5: Distribution of isolated bacteria by specimen types

\begin{tabular}{|c|c|c|c|c|c|c|c|c|c|c|c|c|c|c|}
\hline \multirow[b]{2}{*}{ Organism } & \multicolumn{12}{|c|}{ Specimen tvpe } & \multirow[b]{2}{*}{ Total } & \multirow[b]{2}{*}{ p-value } \\
\hline & 气 & 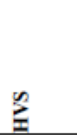 & 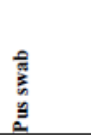 & $\begin{array}{l}\text { लै } \\
\text { है } \\
\text { है } \\
\text { है }\end{array}$ & $\begin{array}{l}\text { लै } \\
\frac{\tilde{E}}{5} \\
\frac{\pi}{m}\end{array}$ & $\frac{\overline{\mathrm{g}}}{\mathrm{m}}$ & 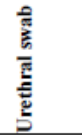 & 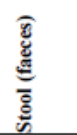 & 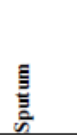 & 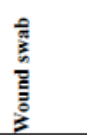 & Еँّ & 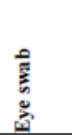 & & \\
\hline E. coli & $87(87.0)$ & $0(0.0)$ & $6(6.0)$ & $0(0.0)$ & $1(1.0)$ & $0(0.0)$ & $2(2.0)$ & $1(1.0)$ & $1(1.0)$ & $2(2.0)$ & $0(0.0)$ & $0(0.0)$ & $100(100.0)$ & \multirow{23}{*}{$<0.001$} \\
\hline$P$ aeruginosa & $0(0.0)$ & $0(0.0)$ & $5(62.5)$ & $1(12.5)$ & $1(12.5)$ & $0(0.0)$ & $1(12.5)$ & $0(0.0)$ & $0(0.0)$ & $0(0.0)$ & $0(0.0)$ & $0(0.0)$ & $8(100.0)$ & \\
\hline K. pneumoniae & $5(29.4)$ & $0(0.0)$ & $3(17.6)$ & $2(11.8)$ & $1(5.9)$ & $0(0.0)$ & $1(5.9)$ & $0(0.0)$ & $1(5.9)$ & $4(23.5)$ & $0(0.0)$ & $0(0.0)$ & $17(100.0)$ & \\
\hline K. oxytoca & $2(33.3)$ & $0(0.0)$ & $3(50.0)$ & $1(16.7)$ & $0(0.0)$ & $0(0.0)$ & $0(0.0)$ & $0(0.0)$ & $0(0.0)$ & $0(0.0)$ & $0(0.0)$ & $0(0.0)$ & $6(100.0)$ & \\
\hline P. mirabilis & $7(70.0)$ & $0(0.0)$ & $2(20.0)$ & $0(0.0)$ & $0(0.0)$ & $0(0.0)$ & $0(0.0)$ & $0(0.0)$ & $0(0.0)$ & $1(10.0)$ & $0(0.0)$ & $0(0.0)$ & $10(100.0)$ & \\
\hline R. ornithinolytica & $0(0.0)$ & $0(0.0)$ & $2(66.7)$ & $0(0.0)$ & $0(0.0)$ & $0(0.0)$ & $0(0.0)$ & $0(0.0)$ & $0(0.0)$ & $1(33.3)$ & $0(0.0)$ & $0(0.0)$ & $3(100.0)$ & \\
\hline E. cloacae & $0(0.0)$ & $0(0.0)$ & $0(0.0)$ & $0(0.0)$ & $1(100.0)$ & $0(0.0)$ & $0(0.0)$ & $0(0.0)$ & $0(0.0)$ & $0(0.0)$ & $0(0.0)$ & $0(0.0)$ & $1(100.0)$ & \\
\hline E. aerogenes & $0(0.0)$ & $0(0.0)$ & $0(0.0)$ & $1(100.0)$ & $0(0.0)$ & $0(0.0)$ & $0(0.0)$ & $0(0.0)$ & $0(0.0)$ & $0(0.0)$ & $0(0.0)$ & $0(0.0)$ & $1(100.0)$ & \\
\hline P. flourescens & $2(100.0)$ & $0(0.0)$ & $0(0.0)$ & $0(0.0)$ & $0(0.0)$ & $0(0.0)$ & $0(0.0)$ & $0(0.0)$ & $0(0.0)$ & $0(0.0)$ & $0(0.0)$ & $0(0.0)$ & $2(100.0)$ & \\
\hline S. odorifera & $0(0.0)$ & $0(0.0)$ & $0(0.0)$ & $1(100.0)$ & $0(0.0)$ & $0(0.0)$ & $0(0.0)$ & $0(0.0)$ & $0(0.0)$ & $0(0.0)$ & $0(0.0)$ & $0(0.0)$ & $1(100.0)$ & \\
\hline A. hydrophila & $0(0.0)$ & $0(0.0)$ & $2(100.0)$ & $0(0.0)$ & $0(0.0)$ & $0(0.0)$ & $0(0.0)$ & $0(0.0)$ & $0(0.0)$ & $0(0.0)$ & $0(0.0)$ & $0(0.0)$ & $2(100.0)$ & \\
\hline Serratia spp & $0(0.0)$ & $0(0.0)$ & $1(33.3)$ & $0(0.0)$ & $1(33.3)$ & $0(0.0)$ & $0(0.0)$ & $0(0.0)$ & $1(33.3)$ & $0(0.0)$ & $0(0.0)$ & $0(0.0)$ & $3(100.0)$ & \\
\hline Pseudomonas spp & $4(36.4)$ & $0(0.0)$ & $0(0.0)$ & $0(0.0)$ & $3(27.3)$ & $0(0.0)$ & $3(27.3)$ & $0(0.0)$ & $0(0.0)$ & $0(0.0)$ & $0(0.0)$ & $1(9.1)$ & $11(100.0)$ & \\
\hline S. aureus & $6(23.1)$ & $0(0.0)$ & $11(42.3)$ & $1(3.8)$ & $2(7.7)$ & $1(3.8)$ & 2 (7.7.) & $0(0.0)$ & $0(0.0)$ & $3(11.5)$ & $0(0.0)$ & $0(0.0)$ & $26(100.0)$ & \\
\hline S. agalactiae & $1(33.3)$ & $1(33.3)$ & $0(0.0)$ & $0(0.0)$ & $0(0.0)$ & $0(0.0)$ & $\begin{array}{ll}1(33.3) \\
\end{array}$ & $0(0.0)$ & $0(0.0)$ & $0(0.0)$ & $0(0.0)$ & $0(0.0)$ & $3(100.0)$ & \\
\hline S. saprophyticus & $2(100.0)$ & $0(0.0)$ & $0(0.0)$ & $0(0.0)$ & $0(0.0)$ & $0(0.0)$ & $0(0.0)$ & $0(0.0)$ & $0(0.0)$ & $0(0.0)$ & $0(0.0)$ & $0(0.0)$ & $2(100.0)$ & \\
\hline S. pyogenes & $0(0.0)$ & $0(0.0)$ & $0(0.0)$ & $1(100.0)$ & $0(0.0)$ & $0(0.0)$ & $0(0.0)$ & $0(0.0)$ & $0(0.0)$ & $0(0.0)$ & $0(0.0)$ & $0(0.0)$ & $1(100.0)$ & \\
\hline E. faecalis & $9(81.8)$ & $1(9.1)$ & $0(0.0)$ & $0(0.0)$ & $0(0.0)$ & $0(0.0)$ & $0(0.0)$ & $0(0.0)$ & $0(0.0)$ & $0(0.0)$ & $1(9.1)$ & $0(0.0)$ & $11(100.0)$ & \\
\hline E. faecium & $0(0.0)$ & $\frac{1}{0(0.0)}$ & $0(0.0)$ & $0(0.0)$ & $0(0.0)$ & $0(0.0)$ & $\begin{array}{l}0(0.0) \\
0(0)\end{array}$ & $0(0.0)$ & $\frac{0(0.0)}{0(0.0)}$ & $\frac{0.07}{1(100.0)}$ & $\frac{1(0.1)}{0(0.0)}$ & $0(0.0)$ & $\frac{11(100.0)}{1(100.0)}$ & \\
\hline MRSA & $0(0.0)$ & $0(0.0)$ & $1(100.0)$ & $0(0.0)$ & $0(0.0)$ & $0(0.0)$ & $0(0.0)$ & $0(0.0)$ & $0(0.0)$ & $0(0.0)$ & $0(0.0)$ & 00.00 & $1(100.0)$ & \\
\hline P. vulgaris & $1(33.3)$ & $0(0.0)$ & $1(33.3)$ & $0(0.0)$ & $0(0.0)$ & $0(0.0)$ & $0(0.0)$ & $0(0.0)$ & $0(0.0)$ & $1(33.3)$ & $0(0.0)$ & $0(0.0)$ & $3(100.0)$ & \\
\hline A. iwoffii & $1(100.0)$ & $0(0.0)$ & $0(0.0)$ & $0(0.0)$ & $0(0.0)$ & $0(0.0)$ & $0(0.0)$ & $0(0.0)$ & $0(0.0)$ & $0(0.0)$ & $0(0.0)$ & $0(0.0)$ & $1(100.0)$ & \\
\hline A. baumannii & $1(100.0)$ & $0(0.0)$ & $0(0.0)$ & $0(0.0)$ & $0(0.0)$ & $0(0.0)$ & $0(0.0)$ & $0(0.0)$ & $0(0.0)$ & $0(0.0)$ & $0(0.0)$ & $0(0.0)$ & $1(100.0)$ & \\
\hline
\end{tabular}

Table 5 shows the most common bacteria isolated by specimen types and we found that most of the bacteria were isolated from urine specimens, pus swabs and 
wound swabs and very few bacteria was isolated from blood and stool (faeces). E. coli was the most commonly isolated bacterial species in urine, $87(87.0 \%)$ but S. aureus was more frequently isolated in pus swabs, $11(42.3 \%)$ and this association was statistically significant $(\mathrm{p}<0.001)$. It was of great note that Enterococcus faecalis was commonly isolated from urine specimens $81.8 \%(9 / 11, \mathrm{p}<0.001)$.

\section{Distribution of isolated bacterial species by demographic factors}

In table 6 we analyzed the association between demographics and isolated bacteria. There were no statistically significant differences in the patterns of organisms found in each of the three locations and among different age groups ( $p$ $=0.296$ and $p=0.446$ ). In contrast, we found a statistically significant difference in the organism isolation pattern between men and women ( $\mathrm{p}<0.001)$. Most of E. coli species $(69.0 \%)$ were isolated from women while $80.8 \%$ of $\mathrm{S}$. aureus were isolated in men. E. faecalis was almost equally isolated between male and female sexes $(54.5 \%$ and $45.5 \%$, respectively).

Table 6: Distribution of isolated bacteria by demographics

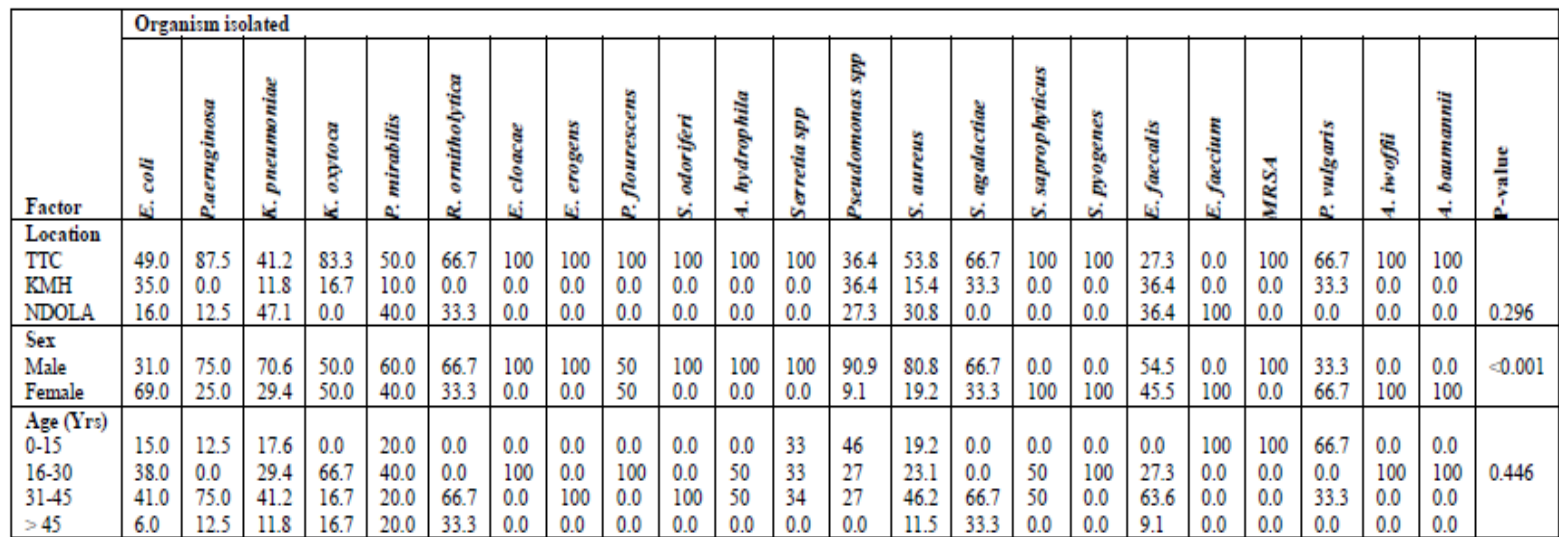

TTC=Trident Town Clinic; KMH=Kansanshi Mine Hospital

Factors that independently predict the isolation of most common bacteria.

Table 7: Logistic regression for the isolation of different bacteria

\begin{tabular}{|c|c|c|c|c|}
\hline $\begin{array}{l}\text { Isolated } \\
\text { organism }\end{array}$ & Variable & OR & $\begin{array}{l}95 \% \text { C.I } \\
\text { for OR }\end{array}$ & p-value \\
\hline \multirow[t]{2}{*}{ E. coli } & Sex, male & 2.93 & $1.46-5.91$ & 0.003 \\
\hline & Age & 1.02 & $0.69-1.51$ & 0.919 \\
\hline \multirow[t]{2}{*}{ E. faecium } & Sex, male & 0.76 & $0.2-2.83$ & 0.677 \\
\hline & Age & 1.74 & $0.72-4.24$ & 0.221 \\
\hline \multirow[t]{2}{*}{ K. pneumoniae } & Sex, male & 0.66 & $0.19-2.25$ & 0.504 \\
\hline & Age & 1.05 & $0.59-1.87$ & 0.868 \\
\hline \multirow[t]{2}{*}{ P. mirabilis } & Sex, male & 0.68 & $0.15-3.05$ & 0.615 \\
\hline & Age & 0.95 & $0.45-2.01$ & 0.890 \\
\hline \multirow{2}{*}{ S. agalactiae } & Sex, male & 0.29 & $0.09-0.91$ & 0.033 \\
\hline & Age & 1.07 & $0.66-1.73$ & 0.790 \\
\hline \multirow[t]{2}{*}{ S. aureus } & Sex, male & 0.07 & $0.01-0.66$ & 0.019 \\
\hline & Age & 0.32 & $0.15-0.70$ & 0.004 \\
\hline \multicolumn{5}{|c|}{$\begin{array}{l}\text { Logistic regression for the isolation of different bacteria. } \\
\text { Coefficients expressed as Odds Ratios. Adjusted for Site of } \\
\text { Collection and Facility Location. Age categorized in periods of } 15 \\
\text { years. }\end{array}$} \\
\hline
\end{tabular}

In order to analyse the potential relationship between the presence of the most commonly isolated bacteria, age and sex of the patients we performed a logistic regression adjusting for site of collection (Urine tract, Ear, Skin or Others) and location of the health care facility (TTC, $\mathrm{KMH}$ or Ndola).

With regards to sex or gender, being male independently increased the chance of being isolated with E. coli by the factor of 2.93 (OR:2.93; 1.46-5.91 95\% C.I; $\mathrm{p}=$ 0.003 ) and being female increased the odds by a factor of $3.44(1 / 0.29)$ times higher of being isolated with $\mathrm{S}$. agalactiae (OR:0.29; 0.09-0.91 95\% C.I; $p=0.033$ ). We further found a statistically significant association between being female and having 14.28 (1/0.07) times higher chance of isolating $\mathrm{S}$. aureus than males and statistically significant evidence of an association between being younger and isolating $\mathrm{S}$. aureus with patients under 15 having 9.36 times more probabilities of being isolated 
with S. aureus than those over 45 years old as shown in table 7.

\section{Bacterial susceptibility profiles of most commonly isolated bacteria against commonly used antibiotics}

The susceptibility profiles of the most commonly isolated bacteria were evaluated. We found that E. coli was highly resistant to amoxicillin (95.0\%), Ampicillin (90.0\%) and Cotrimoxazole (77.0\%). In contrast, E. coli was highly sensitive to Amikacin (96.0\%), Ertapenem $(91.0 \%)$ and Ceftriaxone $(80.0 \%)$. S. aureus species that were isolated were fairly sensitive to Gentamicin (65.4\%) and Clindamycin $(46.2 \%)$ but highly resistant to Cotrimoxazole (80.8\%). Table 8 shows various proportions of the susceptibility profiles for the most commonly isolated bacteria.

Table 8: Antibiotic susceptibility profiles of the most commonly isolated bacteria within MBHS facilities.

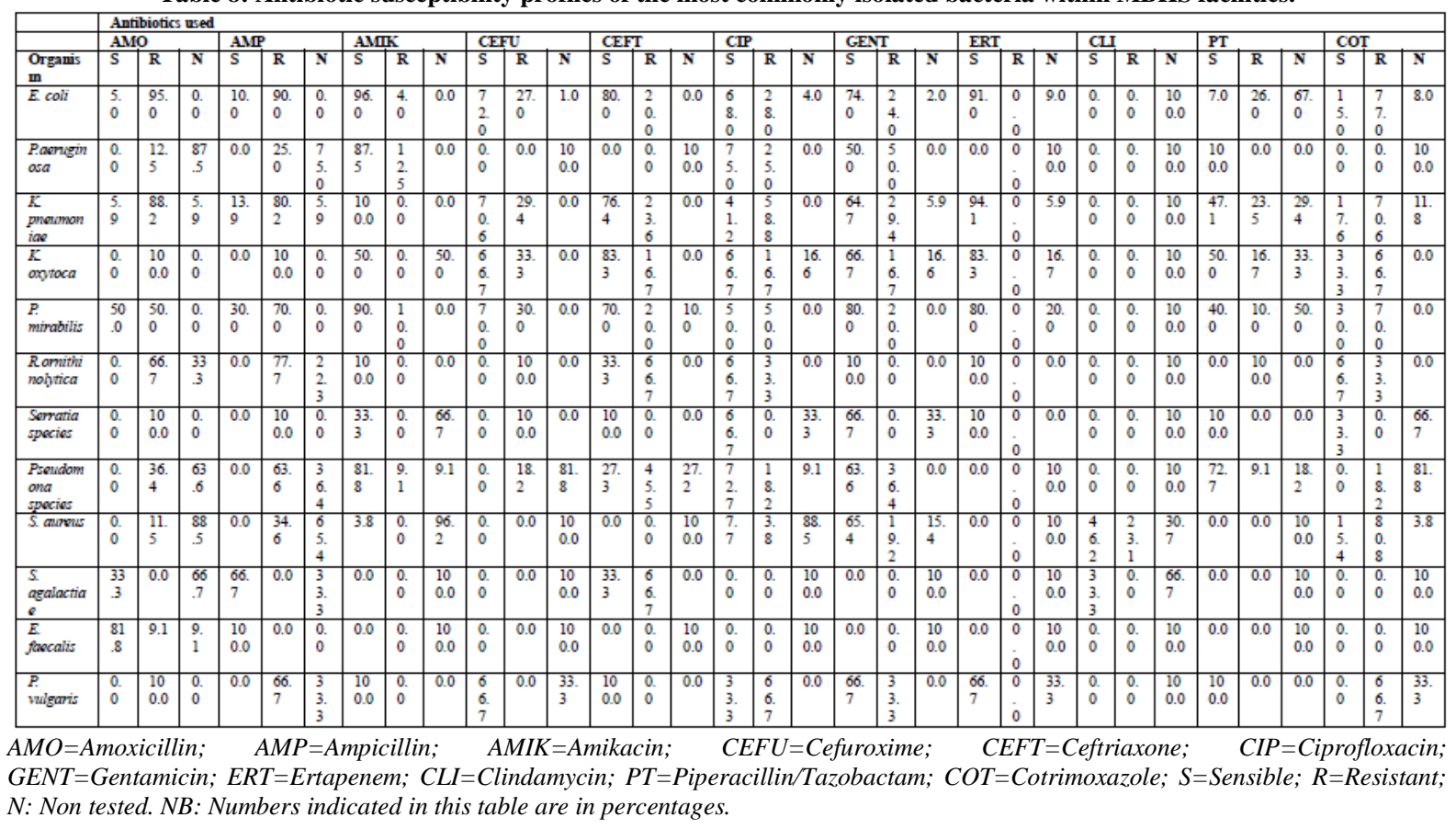

\section{DISCUSSION}

This study aimed at evaluating the distribution of bacteria isolated from various specimens indicated for culture and their antibiotic susceptibility profiles within Mary Begg health services' facilities.

Among the specimens that were submitted for culture, urine was the most common, and with the highest growth for organisms. This indicates that among the bacterial infections that most patients present with within MBHS, urinary tract infection (UTI) is quite common and this is in agreement with other studies that have indicated that UTIs are the third most frequent type of infection in human medicine third to respiratory and gastrointestinal infections. [12-15] Despite stool and blood cultures also being highly requested, there was meagre growth from these specimens and this could be due to the irrational prescription of broad-spectrum antibiotics before the specimen are submitted thereby inhibiting bacterial growth and promoting for more bacterial resistance to antimicrobials.

Escherichia coli was the most commonly isolated organism and a large proportion of it was isolated from urine indicating that E. coli is the major cause of UTI for most patients who present clinically with UTI. This finding agrees with what has been published in many pieces of literature regarding causative agents of UTIs. ${ }^{[16-19]}$ As shown in this study as well as other studies, E. coli is the most common cause of UTI 
because of its many virulence factors which help to fight host defense mechanisms and injure the tissues. Among others, these virulence factors include aerobactin system, adhesion molecules such as pili, $\mathrm{K}$ capsule, cytotoxic necrotizing factor 1 and hemolysin that are contributing virulence factors of E.coli in the pathogenesis of UTI. [12] The dominance of UTI in developing countries can be attributed to deprived sanitation, living method, undernourishment, and ecological stipulation and pregnancy in women. ${ }^{[14]}$

S. aureus was the second most isolated bacterium and majority of it was isolated from pus swabs and urine which indicates that this bacterium also contributes significantly to pus producing infections or wounds as well as UTIs. These findings are in accordance with Singh el al, 2019 and Adhikari et al, 2017 who reported S. aureus to be the most common pus producing organism for soft tissue and wound infections. ${ }^{[20,21]}$

Although not among the most isolated bacteria, $\mathrm{E}$ faecalis was almost equally isolated among male and female patients in MBHS among other UTI causative pathogens. Among men, the organism is prominently isolated among those with or previously with urinary catheters or inserted instruments along the urinary tract. ${ }^{[22]}$ There is a need to identify the predictive causative factors contributing to males being infected with this organism among MBHS facilities. This is because it is an important emerging opportunistic infection that fears the development of Vancomycin Resistance, since it possesses vancomycin resistant enterococcus genes (VRE genes), and a wide range of virulence factors, and being a threat in treatment as they carry numerous transmissible virulent factors/genes (Transposons) among and across organisms as shown in many studies. [23-26] The good picture in this finding is that there was no significant resistance exhibited by the organism.

The distribution of isolated bacteria by gender found that most of E. coli which has also been identified as a major cause of UTI, was isolated more in female patients than male patients. Since E. coli is an enterobacteriaceae, its predominance in females can be due to squatness of female urethra, frequent vaginal colonization, and interference of urine flow as well as complete bladder emptying from prolapse resulting in urinary retention and urinary incontinence which makes it easy for contamination with fecal flora. ${ }^{[14,17,27]}$

Gender and age were also found to be factors that could predict the type of bacteria isolated. Male gender had higher chances of having E. coli isolated compared to women and this could be due to lack of normal flora in the male urethra and as such whenever E. coli and other microorganisms gains entry to the urethral opening, it would result in infection. Young age was also found to be associated with higher chances of $\mathrm{S}$. aureus isolation and this could be explained by weak immune system and/or poor personal hygiene. ${ }^{[14]}$

The emergence and spread of antibiotic-resistant pathogens is a major public health threat. Resistant pathogens especially enterobacteriaceae are able to withstand high doses of antibiotics with various chemical structures and mechanisms of action. Enterobacteriaceae such as E. coli exhibit important mechanisms to avoid lethal doses of drugs by possessing enzymes such as aminoglycoside degrading and betalactamase enzymes, antibiotic target alteration, decreased uptake of antibiotics and overexpression of efflux proteins. ${ }^{\text {[28] }}$

In this study, E. coli was found to have a high resistance prevalence to Amoxicillin and Ampicillin (over 90\% resistance prevalence). However, it was noted that isolated E. coli spp were very sensitive to Amikacin, Ertapenem and Ceftriaxone and this is in tandem with other studies. [13, 17] Contrary to our findings, studies that were done in Nepal and Pakistan found that E. coli was highly sensitive to Ampicillin and less sensitive to Amikacin respectively. [12, 14] This difference in the susceptibility profiles of $\mathrm{E}$. 
coli could be attributed to differences in the bacterial distribution among these regions as well as antibiotic utilization. In Zambia, it is common practice for community pharmacies to sell and dispense nonprescribed antibiotics. Amoxicillin and Ampicillin are amongst these antibiotics. ${ }^{[29}$, 30] This would therefore contribute to the high resistance of amoxicillin and ampicillin observed amongst the isolated bacteria. Aminoglycosides as well as Carbapenems are not readily available in public health facilities and also not well known to members of the community and are as such less likely to be bought from community pharmacies thereby contributing to lower resistance. Most of the microorganisms that were isolated in this study did not show much resistance against commonly used antibiotics. This reflects the antibiotic stewardship program that has been implemented within Mary Begg Health Service in an attempt to combat antibiotic resistance as recommended by WHO. ${ }^{[31-33]}$

\section{CONCLUSION}

The results of this study have demonstrated that Gram negative bacilli are the most prevalent bacteria causing infections among patients attending Mary Begg Health facilities. Escherichia coli and Staphylococcus aureus were found to be the most commonly isolated microorganisms from urine and wound swabs respectively indicating that these bacteria are the major cause of UTIs and soft tissue infections in patients within Mary Begg health facilities. The study also found that E. coli was highly resistant to amoxicillin (95.0\%), Ampicillin $(90.0 \%)$ and Cotrimoxazole $(77.0 \%)$. In contrast, E. coli was highly sensitive to Amikacin (96.0\%), Ertapenem (91.0\%) and Ceftriaxone $(80.0 \%)$. S. aureus species that were isolated were fairly sensitive to Gentamicin (65.4\%) and Clindamycin (46.2\%) but highly resistant to Cotrimoxazole $(80.8 \%)$.

\section{LIMITATIONS}

Being a retrospective study dealing with records only, it was not possible to follow up the specimens for a detailed molecular reasoning. The data presented might not have a true picture of samples as data could be missed during data collection. The sample size was further reduced based on the same grounds as most of the information was missing and that credited for exclusion. The antibiogram used was not all inclusive but representative. This means that only limited antibiotics were studied, making it difficult for the researchers to comment even on other locally common antibiotics used in other facilities in Zambia. Because AMR patterns are more defined based on local behaviors, this study cannot be generalized to infer pictures of other facilities and or communities except the studied population.

\section{ACKNOWLEDGMENTS}

The authors thank the Mary Begg Health Services administration for providing access to patient data and clinical records, and the funding for the study.

\section{Authors' Contributions}

SM and MC developed the conception and design of the study; SM, $\mathrm{MC}$, PS, BM and WS handled data collection; SM and MC did data analysis and drafting of the manuscript; SM, MC, PS, BM, VJ, JR, MK and WS were responsible for reviewing of the manuscript. All authors critically revised and approved the final version of the manuscript.

\section{Funding}

This study was funded by Mary Begg Health Services

\section{Disclaimer}

The authors reserve the rights to all the views reflected in this article.

Ethical Approval: Approved 


\section{REFERENCES}

1. Olufadi-Ahmed, H., A. Aliyue, M. Davide, A. Kola-Mustaphae, and A. Diyaolu, Antibiotic Susceptibility Profile of Uropathogens Isolated from Pregnant Women in Selected Hospitals in Ilorin. Nigerian Journal of Pharmaceutical Research, 2019. 15(1): p. 45-51.

2. Padiyara, P., H. Inoue, and M. Sprenger, Global governance mechanisms to address antimicrobial resistance. Infectious Diseases: Research and Treatment, 2018. 11: p. 1178633718767887.

3. Dugassa, J. and N. Shukuri, Review on Antibiotic Resistance and its Mechanism of Development. Journal of Health, Medicine and Nursing, 2017. 1(3): p. 117.

4. von Wintersdorff, C.J., J. Penders, J.M. van Niekerk, N.D. Mills, S. Majumder, L.B. van Alphen, P.H. Savelkoul, and P.F. Wolffs, Dissemination of antimicrobial resistance in microbial ecosystems through horizontal gene transfer. Frontiers in microbiology, 2016. 7: p. 173.

5. Asante, K.P., E.A. Boamah, M.A. Abdulai, K.O. Buabeng, E. Mahama, F. Dzabeng, E. Gavor, E.A. Annan, S. Owusu-Agyei, and M. Gyansa-Lutterodt, Knowledge of antibiotic resistance and antibiotic prescription practices among prescribers in the Brong Ahafo Region of Ghana; a cross-sectional study. BMC health services research, 2017. 17(1): p. 422.

6. Ferri, M., E. Ranucci, P. Romagnoli, and V. Giaccone, Antimicrobial resistance: a global emerging threat to public health systems. Critical reviews in food science and nutrition, 2017. 57(13): p. 2857-2876.

7. Berha, A., D. Amin, and M. Alebachew, Awareness and Beliefs of Antimicrobial Resistance among Health Professionals working at Tikur Anbessa Specialized Hospital, Addis Ababa: Ethiopia. J Bioanal Biomed, 2017. 9: p. 123-129.

8. Jamhour, A., A. El-Kheir, P. Salameh, P.A. Hanna, and H. Mansour, Antibiotic knowledge and self-medication practices in a developing country: A cross-sectional study. American journal of infection control, 2017. 45(4): p. 384-388.
9. Raza, F., H. Zafar, and L. Ge, Emerging trend in antibiotic resistance: Global views by Health Care Professionals. International Journal of Basic Medical Sciences and Pharmacy (IJBMSP), 2017. 7(1).

10. Ayukekbong, J.A., M. Ntemgwa, and A.N. Atabe, The threat of antimicrobial resistance in developing countries: causes and control strategies. Antimicrobial Resistance \& Infection Control, 2017. 6(1): p. 47.

11. McDermott, P.F., G.H. Tyson, C. Kabera, Y. Chen, C. Li, J.P. Folster, S.L. Ayers, C. Lam, H.P. Tate, and S. Zhao, Wholegenome sequencing for detecting antimicrobial resistance in nontyphoidal Salmonella. Antimicrobial agents and chemotherapy, 2016. 60(9): p. 5515-5520.

12. Moqaddes, S., R. Zulfiqar, M. Gohar, and H. Qaiser, Bacterial urinary tract infections and their association with age, gender and socioeconomic status. Biologia Pakistan, 2018. 8: p. 9.

13. Ali, I., M. Shabbir, and N.U. Iman, Antibiotics susceptibility patterns of uropathogenic E. coli with special reference to fluoroquinolones in different age and gender groups. JPMA, 2017. 67(1161).

14. Yadav, K. and S. Prakash, Screening of ESBL producing multidrug resistant $\mathrm{E}$. coli from urinary tract infection suspected cases in southern Terai of Nepal. J Infect Dis Diagn, 2017. 2(116): p. 2.

15. Gajdács, M. and E. Urbán, Resistance trends and epidemiology of citrobacterenterobacter-serratia in urinary tract infections of inpatients and outpatients (RECESUTI): a 10-year survey. Medicina, 2019. 55(6): p. 285.

16. Erb, S., R. Frei, S. Tschudin Sutter, A. Egli, M. Dangel, G. Bonkat, and A.F. Widmer, Basic patient characteristics predict antimicrobial resistance in E. coli from urinary tract specimens: a retrospective cohort analysis of 5246 urine samples. Swiss medical weekly, 2018. 148(4546).

17. Naqid, I.A., A.A. Balatay, N.R. Hussein, H.A. Ahmed, K.A. Saeed, and S.A. Abdi, Bacterial Strains and Antimicrobial 
Susceptibility Patterns in Male Urinary Tract Infections in Duhok Province, Iraq. Middle East Journal of Rehabilitation and Health Studies, 2020. 7(3).

18. Haddad, J.M., E. Ubertazzi, O.S. Cabrera, M. Medina, J. Garcia, S. RodriguezColorado, E. Toruno, P.K. Matsuoka, and E. Castillo-Pino, Latin American consensus on uncomplicated recurrent urinary tract infection- 2018. International urogynecology journal, 2020. 31(1): p. 3544.

19. Staji, H., M. Rassouli, and S. Jourablou, Comparative virulotyping and phylogenomics of Escherichia coli isolates from urine samples of men and women suffering urinary tract infections. Iranian journal of basic medical sciences, 2019. 22(2): p. 211.

20. Singh, A., V. Verma, and R. Singh, Antibiotic Sensitivity Pattern of Pathogens Isolated from Pus Culture-A Tertiary Care Hospital Based Study. Journal of Nepalgunj Medical College, 2019. 17(2): p. 70-74.

21. Adhikari, R., N.D. Pant, S. Neupane, M. Neupane, R. Bhattarai, S. Bhatta, R. Chaudhary, and B. Lekhak, Detection of methicillin resistant Staphylococcus aureus and determination of minimum inhibitory concentration of vancomycin for Staphylococcus aureus isolated from pus/wound swab samples of the patients attending a tertiary care hospital in Kathmandu, Nepal. Canadian Journal of Infectious Diseases and Medical Microbiology, 2017. 2017.

22. Madrazo, M., A. Esparcia, J. Alberola, A. Ferrer, J.M. Eiros, J.M. Nogueira, and A. Artero, Predictive factors for Enterococcus faecalis in complicated community-acquired urinary tract infections in older patients. Geriatrics \& Gerontology International, 2020. 20(3): p. 183-186.

23. Weng, P.L., R. Ramli, M.N. Shamsudin, Y.-K. Cheah, and R.A. Hamat, High genetic diversity of Enterococcus faecium and Enterococcus faecalis clinical isolates by pulsed-field gel electrophoresis and multilocus sequence typing from a hospital in Malaysia. BioMed research international, 2013. 2013.

24. Bourafa, N., C. Abat, L. Loucif, A.O. Olaitan, A.A. Bentorki, N. Boutefnouchet, and J.-M. Rolain, Identification of vancomycin-susceptible major clones of clinical Enterococcus from Algeria. Journal of global antimicrobial resistance, 2016. 6: p. 78-83.

25. Zheng, J.-X., Y. Wu, Z.-W. Lin, Z.-Y. Pu, W.-M. Yao, Z. Chen, D.-Y. Li, Q.-W. Deng, D. Qu, and Z.-J. Yu, Characteristics of and virulence factors associated with biofilm formation in clinical Enterococcus faecalis isolates in China. Frontiers in microbiology, 2017. 8: p. 2338.

26. Zalipour, M., B.N. Esfahani, M. Halaji, A. Azimian, and S.A. Havaei, Molecular Characterization of VancomycinResistant Enterococcus faecalis Among Inpatients At Iranian University Hospitals: Clonal Dissemination Of ST6 And ST422. Infection and Drug Resistance, 2019. 12: p. 3039.

27. Chu, C.M. and J.L. Lowder, Diagnosis and treatment of urinary tract infections across age groups. American journal of obstetrics and gynecology, 2018. 219(1): p. 40-51.

28. Odongo, I., R. Ssemambo, and J.M. Kungu, Prevalence of Escherichia Coli and Its Antimicrobial Susceptibility Profiles among Patients with UTI at Mulago Hospital, Kampala, Uganda. Interdisciplinary Perspectives on Infectious Diseases, 2020. 2020.

29. Kalungia, A.C., J. Burger, B. Godman, J.d.O. Costa, and C. Simuwelu, Nonprescription sale and dispensing of antibiotics in community pharmacies in Zambia. Expert review of anti-infective therapy, 2016. 14(12): p. 1215-1223.

30. Kalonga, J., J. Hangoma, M.B.D. Munkombwe, and S. Mudenda, Antibiotic Prescribing Patterns in Paediatric Patients at Levy Mwanawasa University Teaching Hospital in Lusaka, Zambia. International Journal of Pharmaceutics \& Pharmacology, 2020. 4(1).

31. Kalungia, A.C., H. Mwambula, D. Munkombwe, S. Marshall, N. Schellack, C. May, and B. Godman, Antimicrobial 
stewardship knowledge and perception among physicians and pharmacists at leading tertiary teaching hospitals in Zambia: implications for future policy and practice. Journal of Antimicrobial Chemotherapy, 2019.

32. Johnson, A.P., B. Muller-Pebody, E. Budd, D. Ashiru-Oredope, D. Ladenheim, D. Hain, R. Hope, A. Bhattacharya, S. Elgohari, and R. Guy, Improving feedback of surveillance data on antimicrobial consumption, resistance and stewardship in England: putting the data at your Fingertips. Journal of Antimicrobial Chemotherapy, 2017. 72(4): p. 953-956.

33. Godman, B., J. Fadare, D. Kibuule, L. Irawati, M. Mubita, O. Ogunleye, M.
Oluka, B.D.A. Paramadhas, J. de Oliveira Costa, and L.L.P. de Lemos, Initiatives across countries to reduce antibiotic utilisation and resistance patterns: impact and implications, in Drug resistance in bacteria, fungi, malaria, and cancer. 2017, Springer. p. 539-576.

How to cite this article: Mubita SM, Simbile W, Mulunda B et.al. Characterization and antimicrobial susceptibility profiles of bacteria isolated from various specimens among mary begg health facilities. Int $J$ Health Sci Res. 2021; 11(5): 41-52. DOI: https://doi.org/10.52403/ijhsr.20210506 